\title{
INMIGRANTES DELINCUENTES EN PRENSA: UN PASO MÁS ALLA'DEL DISCURSO DE LA INMIGRACIÓN COMO PROBLEMA
}

\author{
CRIMINAL IMMIGRANTS PUBLISHED: A STEP BEYOND THE SPEECH OF \\ IMMIGRATION AS A PROBLEM
}

\section{RESUMEN:}

Los inmigrantes suelen ser considerados ilegales o incluso delincuentes por los medios de comunicación, cuyos discursos son cada vez más duros $\mathrm{y}$, además, los responsabiliza de un aumento en la delincuencia. En este trabajo, analizaremos cómo estos discursos han aumentado la xenofobia y el racismo en la sociedad y la importancia de la prensa ante este problema.

Palabras claves:

Discurso, inmigrante, inmigración, delincuente.

\section{Abstract:}

Immigrants are usually considered as illegal and even delinquent people by media, whose speeches are getting harsher and what's more make them responsible for an increment in the delinquency. In this work, we will analyse how these speeches have increased xenophobia and racism in the society and the importance of the press before this problem.

\section{KEY WORD:}

Woman, East, society, feminism. 
La construcción de un espacio europeo unificado, tanto en el plano físico (el denominado espacio Schengen) como en el simbólico, pasa por el establecimiento de unas fronteras bien delimitadas y protegidas del(os) exterior(es). Las fronteras protegidas tecnológica y militarmente ${ }^{1}$ tienen su correlato simbólico en los discursos sociales que señalan quienes están fuera amenazando con la invasión: esos nuevos 'extraños' son los inmigrantes que son definidos como 'los otros', los ajenos, los delincuentes, los marginados... La empatía y el conocimiento es cada vez más difícil con estos parámetros discursivos porque además, los de "este lado" de la frontera también somos categorizados como homogéneos y pero nos definimos como buenos ${ }^{2}$

Los inmigrantes no son ciudadanos ${ }^{3}$, es más, muchos de ellos, los llamados 'ilegales' desde los medios de comunicación, jurídicamente ni son. Algunos discursos van más allá de la invisibilización o de la asunción del fenómeno migratorio como un problema, dando un paso significativo hacia discursos criminalizadores.

El año 2002 supuso un salto cualitativo, en este progresivo endurecimiento de los discursos que se (re)producen en los medios de comunicación españoles acerca del fenómeno inmigratorio. Por primera vez, aparecía en las páginas de las dos cabeceras de referencia nacional EL PAÍS y EL MUNDO un discurso en el que se vinculaba explícitamente la delincuencia con la inmigración. De la mano de la argumentación política y enmarcada en un debate más general sobre la delincuencia y la inseguridad ciudadana, se responsabilizó a los inmigrantes de un aumento desproporcionado de ambas, alimentado con tal generalización los fuegos del miedo, el racismo y la xenofobia.

\section{El Valor Social de la Prensa y su Interés como Objeto de Estudio}

Los discursos que crean y recrean de los medios de comunicación, y en especial de la prensa escrita de referencia-EL PAÍ́ y EL MUNDO- tienen especial interés por ser

1 Ejemplifican esto titulares publicados también en el 2002 como: 'Londres planea frenar la inmigración ilegal con buques de guerra en el Mediterráneo' (EL MUNDO, 24/05/02); “La UE estudia planes de repatriación masiva de 'clandestinos' (EL PAÍS, 14/09/02); El Partido Popular de Fuerteventura pide buques de la Armada para frenar la llegada de pateras' (EL PAÎS, 25/01/02); 'Policías y servicios barcos para "impedir la invasión de inmigrantes" (EL MUNDO 29/03/02); 'El Gobierno activa el control electrónico para detectar pateras' (EL MUNDO, 12/08/02)'

2 Esta estrategia discursiva, como veremos a posteriori es definida por Van Dijk como el Cuadrado Ideológico.

3 Entendemos la Ciudadanía en este contexto, vinculada al concepto de Estado-Nación. Hablamos, siguiendo a autores como De Lucas (2002) o Zapata (2002) conjunto de derechos derivados de la vinculación de los sujetos (por sangre o por ascendencia) a un territorio. Desde el punto de vista de la igualdad de derechos, los inmigrantes se han convertido en sujetos sociales de segundo orden regidos por una legislación distinta del resto de la sociedad, la ley de Extranjería, cuyo sentido último es despojar de derechos como el de asociación, el de reunión, el de huelga... [0]a los inmigrantes. [0] los medios, el espacio en el que negocian y articulan, de forma dinámica y continuada, las imágenes de diversos colectivos e individuos.

La selección de los periódicos de EL MUNDO y EL PAÍS como objetos susceptibles de investigación responde primeramente a la consideración social que tienen ambas cabeceras, tanto por su tirada- nacional y de las más numerosas entre la prensa escritacomo por su prestigio como prensa 'seria'. Además, la prensa escrita sigue siendo considerada un referente y una fuente de información, para el resto de los medios de comunicación, a pesar de ser minoritario su público comparado con los audiovisuales más masivos. El periódico es considerado socialmente el medio en el que se le otorga un mayor espacio a la reflexión (sobre todo por su propia naturaleza lectora).

Es importante además, recordar rol que los medios de comunicación desempeñan en nuestras Sociedades Complejas. Los medios son actualmente, una de las instancias de socialización más importantes, pues tenemos que tener en cuenta que tanto el papel de la escuela cómo el de la familia están siendo progresivamente desplazados por los éstos como ámbitos de socialización primaria. Esto supone que los medios de comunicación socialmente son una fuente de conocimiento y de formación de opiniones. Por ello, tienen la capacidad de fijar la conciencia social mayoritaria acerca de temas a los que los lectores no tienen acceso cotidiano más directo. En el caso de la inmigración, la distancia y el desconocimiento real es especialmente relevante, entre otras cosas, porque los inmigrantes son identificados como 'otros', 'los ajenos'. Esta misma definición social es la que reciben los delincuentes. Según Hess (1986), los delincuentes están definidos en prensa por la anormalidad, la distancia, la locura, la imposibilidad de empatía... Estos discursos sociales pueden llegar a ser tan potentes que en ocasiones, se asumen aunque pueda contradecir la realidad cotidiana, porque los medios son espacios poderosos de legitimación social.

El análisis del discurso que vamos a abordar aquí, es necesariamente interdisciplinar. Para entender el vínculo discursivo entre delincuencia e inmigración y sus relacione con otros discursos que también aparecen en prensa, tenemos que contextualizarlo diacrónica y sincrónicamente, apoyándonos en otras disciplinas como la Sociología, la Criminología, la Filosofía del Derecho, la Antropología o la Historia... que ayuden a enriquecer nuestro análisis comunicativo.

Esta relación compleja y muchas veces opaca entre lo social y lo discursivo es el principal objeto de estudio del Análisis Crítico del Discurso. Más que un paradigma de investigación o una disciplina científica, el Análisis Crítico supone una forma distinta y comprometida ${ }^{4}$ de observar los textos, entendiendo este concepto de forma

4 Esa forma de mirar implica la atención hacia determinados temas como el racismo o el sexismo en los medios de comunicación con la intención de desvelar relaciones de poder y desigualdad no explícitas. 
amplia. Relacionando textos con contextos (mediáticos pero también sociales, es decir incardinados en espacios y tiempos históricos concretos). Es decir, nos interesan los discursos ${ }^{5}$ periodísticos.

Pretendemos demostrar la estrecha vinculación entre lo social y lo comunicativo, y poner de relieve los filtros y estrategias que se manejaron desde las páginas de EL PAÍS y EL MUNDO para formar la opinión de sus lectores, acerca de un fenómeno- la inmigración- que era conceptualizado como conflictivo, peligroso.

\section{Conceptualización y Discursos. Puntos de Partida}

Podríamos señalar antes que nada, a qué se refieren los medios cuando hablan de inmigrantes, porque los rasgos definitorios no son los denotativos que aparecen en los diccionarios $^{6}$

El Diccionario de la Real Academia considera que: Inmigrar Dicho del natural de un país: llegar a otro país para establecerse en él, especialmente con la idea de formar nuevas colonias o domiciliarse en las ya formadas.

Emigrar. Dicho de una persona, de una familia o de un pueblo. Dejar o abandonar su propio país con ánimo de establecerse en otro extranjero. Ausentarse temporalmente del propio país para hacer en otro, determinadas faenas. Abandonar la residencia habitual dentro del propio país, en busca de mejores medios de vida.

Hemos recogido las dos definiciones por varias razones. Primero porque son conceptos complementarios: el que emigra de un lugar, se convierte en inmigrante al llegar a su destino. Pero además porque ambas definiciones ponen sutilmente de manifiesto, algunas de las diferencias que socialmente existen entre ambos conceptos. Así, el diccionario enfatiza que el emigrante viaja para 'buscar mejores condiciones de vida' o señala que la ausencia puede ser temporal, mientras que en el caso del inmigrante no se señalan las razones de ese viaje, y sólo recoge a los inmigrantes que se establecen permanentemente. A pesar de todo ello, podemos evaluar ambos conceptos como un todo y entresacar tres características, que nos ayudaran a acercarnos a la idea denotativa de inmigración. En estas definiciones se hace énfasis en: el desplazamiento hacia MI territorio desde OTRO territorio para trabajar. Si contrastamos ahora estas tres características, con los textos publicados en prensa que tengan a la inmigración y

5 Entendemos el discurso periodístico, como una forma particular de discurso público que mantiene una estrecha relación, aunque mediada y compleja, con lo social. Consideramos los discursos, prácticas sociales, espacios de producción de sentidos sociales.

6 No podemos afirmar que el significado de las palabras en los diccionarios sea puramente denotativo ya que está elaborado por un conjunto de académicos, es decir que también está en manos de sujetos que tienen una forma determinada, no sólo individual, de mirar y comprender el mundo. Pero es la definición más canónica que socialmente se maneja.

Revista Internacional de Culturas y Literaturas, enero 2005 ISSN: $1885-362$ a los inmigrantes como referentes, podremos acercarnos a la idea de inmigración que mana de los medios de comunicación.

En prensa la concepción de la inmigración como un desplazamiento de un lugar a otro está de alguna forma distorsionada porque la inmigración tiene poco que ver con la emigración. El inmigrante caracterizado, como luego veremos como 'pobre', 'distinto', 'marginado' no tiene nada en común con la idea social de emigrante 'emprendedor', trabajador'... De modo que como inmigrar no tiene que ver con emigrar, lo que queda a los que emprenden del viaje migratorio es, como muy irónicamente señala De Lucas, es ponerse en órbita.

Además, la idea de territorialidad se amplía mucho en los medios. En prensa se habla de inmigrantes en países distintos del nuestro, que según la definición del diccionario sería la referencia espacial. Así, se habla de inmigrantes en EE.UU.7, en Israel, en Gran Bretaña, en Dinamarca, en Italia. Se podría argumentar de los últimos dos países que al pertenecer a la U.E. forman parte de nuestro territorio. Pero, ¿qué vínculo territorial nos une a Israel?, ¿y a EE.UU.?

En realidad, cuando se habla en prensa de inmigrantes en EE.UU. o Israel a lo que se está apelando es una solidaridad supraestatal entre países desarrollados que tienen que 'sufrir' la presencia de inmigrados.

La idea de viajar para mejorar las condiciones de vida mediante el trabajo tampoco es evidente en las páginas de los periódicos. Sobre todo si tenemos en cuenta referencias como las que se hacen a los 'menores inmigrantes' o la confusión entre inmigrantes y asilados políticos 8 . Con titulares como 'La ONU exige al Gobierno que erradique los "malos tratos" a menores inmigrantes ${ }^{\prime 9}$ no se pretende hacer apología del trabajo infantil desde un periódico definido como demócrata porque lo que subyace a la etiqueta de menores inmigrantes es la idea de que la inmigración no siempre está relacionada con el trabajo, con lo que si los inmigrantes no vienen a trabajar se puede caer en la acusación de 'vagos' o incluso de 'delincuentes'.

El concepto mediático de inmigración es por tanto una etiqueta que homogeneiza a colectivos de personas de muy distintas procedencias geográficas, con diferencias de formación, de género o de clase... y pone el acento en dos rasgos: en 'la otredad' (lo

7 'el Reino Unido deportará a los inmigrantes ilegales a los que no conceda el derecho de asilo' (EL PAÍS, 31/05/02), el derecho de asilo sólo puede ser solicitado por refugiados; 'EEUU extrema medidas para 'fichar' a inmigrantes (EL MUNDO, 06/06/02); 'Israel emprende deportaciones masivas de inmigrantes' (EL MUNDO, 03/09/02)

8 Los refugiados están sujetos a protección internacional pero en prensa se confunde por ejemplo: "Italia decreta el estado de emergencia en Sicilia ante el aluvión de refugiados" (publicada en portad 19/03/02 en EL PAÍS), esa misma noticia aparecería en el interior del periódico pero sustituyendo la palabra refugiados por 'inmigrantes'

9 08/06/02 de EL PAÍs

(a) Culturas y Literaturas, enero 2005 
extraño, lo desconocido, lo raro) y en la marginalidad. Los inmigrantes en prensa son individuos procedentes de países en los márgenes de la Globalización internacional ${ }^{10}$ y también progresivamente marginados por la legalidad española, una indefensión jurídica que provoca en ocasiones abusos por parte de los autóctonos ${ }^{11}$.

De esta manera las características de la imagen mediática de la inmigración son:

1. Procedencia del ‘Tercer Mundo (antiguas colonias...).

2. Percibidos como 'pobres'

3.Étnicamente diferenciados

Esta caracterización es muy potente y hace que sujetos que si responderían a las características que entresacamos de la definición del diccionario, 'persona que viaja para trabajar' generalmente no sean concebidos en los medios de comunicación como inmigrantes, y a la inversa personas que no son inmigrantes pero que si parecen responder a la caracterización mediática sean confundidos como tales. Así, por ejemplo, en las noticias de enfermeras españolas que emigran a Gran Bretaña para encontrar trabajo, se habla de futuro, de viaje, de esperanzas, de mejores condiciones de vida... pero no de que se conviertan en inmigrantes. Otro ejemplo, en una noticia ${ }^{12}$ de EL MUNDO que narraba el ataque racista que había sufrido un turista puertorriqueño, en el texto se llegaba a poner en duda la condición de turista del sujeto porque respondía a las tres características que hemos mencionado (procede de un país en desarrollo, es negro y parece no tener dinero).

Para autores como Antonio Izquierdo, el paradigma del inmigrante en el que se sintetizan las características reseñadas ('el extraño' ${ }^{13}$, 'el étnicamente diferenciado', el pobre...) es el magrebí.

\section{Antecedentes Discursivos del Vínculo entre Delincuencia e Inmigración. Evolución del Discurso Problemático de la INMIGRACIÓN}

La progresiva construcción de esta nueva otredad, una de las manifestaciones más evidentes es la vinculación discursiva que nos ocupa, no tiene más de 15 o 20 años,

10 De países que son definidos territorialmente también como 'los otros' en el sentido de que como hemos visto existe un vínculo supraestatal entre países desarrollados en los titulares de prensa.

11 '40 000 pesetas al mes por colchón' (EL PAÍ́, 09/04/02); 'detenidas en Barcelona nueve personas acusadas de engañar a 500 inmigrantes con documentos falsos (EL PAÍ́, 16/02/02); 'Detenido un alcalde del PP por vender carnés de conducir' , en el texto se especifica que eran para inmigrantes
(EL PAÎ́S, 29/08/02); 'Cama a 90 en un edificio en ruinas' (EL PAIIS, 18/01/02)

12 'un puertorriqueño de 41 años muere en el paseo de Recoletos tras sufrir un atraco. La víctima, que pereció en plena calle, había llegado en noviembre a España como turista' (subt) (EL PAÍS, 16/12/02). 13 La palabra extranjero comparte la misma etimología que extraño. Este mismo paralelismo se da en otros idiomas: stranger (en inglés, forastero y extraño); barbaro (latín, extranjero, extraño). momento en el que, según demógrafos como Antonio Izquierdo (1996), el número de inmigrantes comenzó a ser significativo.

Siguiendo a autoras como Wodak (2003), quien hace un especial énfasis en la historicidad de los discursos, podríamos afirmar que el tratamiento mediático de los inmigrantes, tendría varios hitos clave.

En 1992, el asesinato de Lucrecia por un guardia civil que fue definido en prensa como 'el primer asesinato racista en España', caracterizó un periodo que Wilson y Gutiérrez (1985) denominan 'fase de exclusión', en el que la presencia de los inmigrados en las calles iba progresivamente en aumento, pero en las páginas de prensa era muy escasa. Estaba marcada por sucesos aislados e inconexos y el tratamiento periodístico era el propio de la narración de sucesos: algo novedoso, morboso, dramático, con una alta densidad emocional, estereotipado y cercano a lo mítico.

El goteo de sucesos que tenían como protagonistas a los inmigrantes, tanto como víctimas como culpables, se hizo cada vez más continuo y hoy es un tipo de narración muy presente en las páginas de los periódicos que nos ocupan, sobre todo en las secciones o cuadernillos locales. El paradigma de este segundo momento es la narración de la llegada de las pateras que progresivamente y por saturación ha ido perdiendo efectismo dramático, aunque no presencia en la prensa, y consolidando la idea de incontenibilidad, de avalancha.

Entre el año 1999 y 2000 con los ataques racistas de Ca'Anglada y el Ejido, se produjo un crecimiento exponencial del volumen de noticias relacionadas con la inmigración. Desarrolló la idea de inmigración como foco informativo y su correlato en la opinión pública de preocupación social ${ }^{14}$.Actualmente, temas relacionados con la inmigración aparecen casi diariamente en las páginas de prensa. Sólo un dato: en el vaciado de prensa realizado ${ }^{15}$, incluso en el día de la Huelga General (en el que los periódicos no tenían más de 30 páginas) hubo noticias sobre inmigración.

En el progresivo crecimiento del volumen de textos relacionados con la inmigración a lo largo del tiempo, podemos señalar una constante: el enfoque problemático de la inmigración. El problema de la inmigración o los problemas de los inmigrantes, dependiendo del rango ideológico de la cabecera que tratemos, es prácticamentela única forma entender la inmigración. Será pocas veces connotado positivamente: hablamos de unos 20 textos que hacen referencia al aporte demográfico de la inmigración -el texto tipo era el reportaje de tasas de natalidad en el que se enfatizaban los nacimientos

14 Este interés informativo podría darnos algunas claves de porqué repetidamente en los últimos años la inmigración aparece en las encuestas del CIS como tercer o cuatro problema de preocupación de los españoles, tras el paro y el terrorismo.

15 Hablamos de un volumen de textos que excede los 3700 por periódico. 
de inmigrados ${ }^{16}$ de segunda generación- o al aporte económico - en este caso el texto modelo era el reportaje que recogía las cifras de nuevos afiliados extranjeros a la Seguridad Social $)^{17}$. Tampoco será un fenómeno neutro: discursivamente la inmigración no es un Natural Demográfico como la muerte, o el nacimiento, tampoco es un Derecho Universal.

Es en este contexto discursivo problemático, en el que se ha ido construyendo una idea de inmigración homogénea y vinculada al suceso, en el que surge el vínculo discursivo explícito entre delincuencia e inmigración.

\section{Algunas Estrategias Utilizadas en los Textos}

En 2002, y principalmente desde los atriles políticos, se relacionó explícitamente la delincuencia con la inmigración. El debate social, que se prolongó en el tiempo durante todo el año y que fue abierto a primeros de año por el Partido Socialista como forma de atacar al Gobierno, tenía como argumento principal el espectacular crecimiento de la delincuencia y la responsabilidad de la inmigración.

Uno de los elementos argumentativos más potentes fue el uso de la cifra estadística ${ }^{18}$ Los tantos por ciento, y los muchos ceros aparecían con mucha frecuencia en la gran mayoría de los textos en los que se vinculaba de forma más o menos explícita la inmigración con la delincuencia y tenían un valor discursivo importante. Las cifras en prensa son un elemento de credibilidad en los textos. Deudoras de una tradición científica que cree la objetividad y la imparcialidad del número y de un periodismo que aspira a esa misma objetividad, las cifras dan brillantez y veracidad a los textos. El número, es además un concepto abstracto difícil de visualizar.

Además de señalar la legitimidad discursiva que tiene el número- como argumento muy resistente a la puesta en cuestión- interesa analizar la inconsistencia de las cifras,

16 El concepto de inmigrante de segunda generación es problemático porque en realidad los niños nacidos de inmigrantes no han hecho ningún viaje, ni trabajan. Pero hemos encontrado otro concepto apropiado que sea socialmente compartido.

17 Pero además, podemos poner en entredicho esta idea de inmigración aparentemente positiva, porque la concepción de la inmigración que subyace es muy instrumental, 'los inmigrantes son buenos, porque nos sirven'.

18 Ejemplos del alud de cifras que aparecieron en estos textos podemos encontrarlos en titulares como: 'Interior atribuye a la inmigración el aumento de la criminalidad en más de un 9\%. 'EL PAÍS, 03/01/02); 'Interior pide 'tolerancia cero' con el multirreincidente. El Director del a Policía achaca a la inmigración irregular la subida de la delincuencia en un 10,52\%' (subt) (EL PAÍ́s, 11/02/02); 'El Gobierno culpa del aumento de la delincuencia a la inmigración y a la facilidad para denunciar. Interior asegura que el $50 \%$ de los robos con violencia los cometen ciudadanos extranjeros' (antetítulo) (EL PAÍ́s, 05/03/02); 'Rajoy revela que nueve de cada diez nuevos reclusos preventivos son extranjeros. El vicepresidente insisten en atribuir el aumento de la delincuencia a los inmigrantes irregulares' (subt) (EL PAÍS, 07/03/02); 'Interior destaca que la mayoría de los homicidios del 2001 fueron ajustes de cuentas entre extranjeros. La población de los centros penitenciarios sobrepasa los 40 000; casi 10000 de ellos son inmigrantes' (subt) (EL MUNDO, 03/01/02); que en ocasiones variaban del titular de portada al del interior: como en EL MUNDO del 11 febrero 2002 'más de la mitad de los 332147 detenidos fueron extranjeros (portada), 'más de la mitad de los 232000 detenidos fueron extranjeros' (interior).

Autores como García España (2001) o Wagman (2002) si rebatieron insistentemente las cifras que se manejaban en prensa. Argumentaban que no se debía confundir la tasa delictiva de los inmigrantes con la de los extranjeros (en la que estaban incluidos turistas y 'transeúntes'), que no se podía titular mezclando los delitos con las faltas (ya en el caso de los inmigrados un volumen muy importante de detenciones se debían a carecer de documentación, y eso sólo es una falta administrativa), que debíamos comparar la tasa delictiva de los inmigrantes con la Población Activa de los autóctonos, porque la Criminología ha demostrado que son los hombres jóvenes- perfil que coincide con los inmigrantes- los más proclives al delito... Es decir, contrastaban el poderoso y falaz argumento de 'el $50 \%$ de los robos con violencia lo cometen los inmigrantes' ${ }^{19} \mathrm{o}$ 'el $90 \%$ de los presos preventivos es extranjero ${ }^{20 \prime}$ con parámetros reales de la delincuencia extranjera ${ }^{21}$.

Otra característica discursiva de estos textos es el tipo de fuentes periodísticas que se utilizan. La práctica totalidad de este conjunto de textos en los que aparece el binomio delincuencia- inmigración utiliza con exclusividad fuentes institucionales muy cercanas a los medios ${ }^{22}$. Responsables políticos y oposición, Policía, Ministerio del Interior, Instituciones Penitenciarias, el Centro de investigaciones Sociológicas, expertos, columnistas de opinión... dieron forma a un debate generado desde los

\section{05/3/02, EL PAÍS}

20 26/06/02 EL PAÍS

21 Criminólogos como Baratta (1986), García España (2001), Flowers (1988) y sociólogos Manzanos Bilbao (1999), Wacquant (2000), Becker (1971),Varela (1987) han demostrado repetidamente que no se puede establecer una relación causal entre el fenómeno inmigratorio y el delictivo. Entre las teorías que se manejan para explicar la actual sobrerrepresentación de las minorías étnicas (de los inmigrados pero también de minorías autóctonas como los gitanos) en el Sistema Penal Español (en instancias policiales, judiciales y penitenciarias) podemos destacar dos interesantes para nuestro análisis: La llamada teoría del arraigo social de Hirschi,(1969) que afirma que un sujeto es menos proclive a cometer un delito cuanto más lazos sociales (más referentes morales, afectivos...) tenga por el miedo a perderlos. En este sentido, la situación de los inmigrantes se ajusta a esta definición por el propio trayecto migratorio, tienen que reconstruir lazos sociales en una sociedad distinta a la propia, donde además viven condiciones más degradadas que el resto de la población, en situaciones de marginalidad que los teóricos denominan de riesgo delictivo y la Teoría del Etiquetamiento, con la que autores como Goffman, Becker, Dahrendorf, Garfinkel... afirman que: es imposible conoce la criminalidad si no se estudia la acción del sistema penal que la define y reacciona contra ella empezando por las normas abstractas hasta llevar a la acción de las instancias oficiales (Baratta 1986).

22 Estudios etnometodológicos sobre las rutinas periodísticas de obtención de información han demostrado que la consideración de 'fuente fiable' tiene mucho que ver además de con el prestigio social de la fuente de información, con el contacto continuado con los medios de comunicación. En el caso de las instituciones que se citan esto es cierto porque todas ellas cuentas con mecanismos de acceso preferente a los medios de comunicación como son los gabinetes de comunicación, las ruedas de prensa periódicas... 
medios de comunicación. Esto pone de manifiesto la relación de las élites y los medios de comunicación que analiza Van Dijk (1990). Las fuentes oficiales tienen un acceso privilegiado a los medios de comunicación además de una legitimidad de la que no gozan ninguna otra fuente alternativa. Para Fairclough (1998), este acceso privilegiado a los medios de comunicación es una cuestión de poder, de tener voz, además de tener capacidad de transformación social y de negociación. En este sentido, el Análisis Crítico del Discurso tiene como objeto de estudio privilegiado las relaciones de poder como elemento también discursivo. Hace visibles unas relaciones de poder desiguales, que como bien señala Van Dijk, tienen un sustrato de Racismo Institucional, entendido éste como sistema de prejuicios de carácter estructural e histórico, que basado en supuestas diferencias biológicas, que legitima las desigualdades.

El concepto de Cuadrado Ideológico nos ayuda a entender otra de las estrategias básicas presentes en los textos mediáticos que nos interesan y que podríamos llamar 'el nosotros contra ellos'. 'Nosotros' se convierte así en una categoría en la que estaría incluido el periodista, pero también el lector y más generalmente, la Comunidad compartida por ambos ${ }^{23}$. De la misma forma, la categoría 'ellos' se configura también como homogénea, estable y de rasgos fijos, definidos y antagónicos de los 'nuestros'. A partir de esta estrategia se construyen los principales discursos problemáticos acerca de la inmigración que se están viendo aquí.

\section{NOSOTROS ELLOS}

\section{Tipos Básicos de Textos en los que se Vincula Delincuencia con}

\section{INMIGRACIÓN:}

En el análisis de los textos publicados en 2002 en los que se relacione de forma más o menos directa la inmigración con la delincuencia podemos encontrarlos con dos prototipos básicos de textos que hemos denominado: los sucesos étnicos y las declaraciones políticas.

La narración de lo que podemos llamar sucesos étnicos, es decir de textos en los que en la que se hace un énfasis especial en la otredad (la nacionalidad, la religión, el color de la piel...) de la víctima o del culpable se ha convertido en un tipo de textos ya clásicos al hablar de inmigración, muy presente sobre todo en los cuadernillos locales. En nuestro año de investigación se publicaron una media mensual de unos 35 o 40 de este tipo de textos en los cuadernillos de Madrid (EL PAÍs) y unos 50 o 55 en M2 y Madrid (de EL MUNDO) a pesar de ser desaconsejadas repetidamente en los distintos Códigos Deontológicos.

23 Nos referimos aquí al concepto también discursivo de comunidad de sentido que hace referencia a una colectividad (en este caso la sociedad 'de acogida') que comparte valores, creencias, actitudes

$$
\text { Revista Internacional de Culturas y Literaturas, enero } 2005
$$

Hemos de decir que a pesar de la continuidad temporal de este tipo de narración de sucesos- desde los orígenes de las noticias sobre inmigración en el Estado que hemos situado en 1992 con el asesinato de Lucrecia- en los últimos años se ha observado un mayor cuidado en la forma de titular, siendo ya muy raro tanto en EL PAÍs como en EL MUNDO titulares del tipo: 'pakistaní acusado de matar a su compañera a golpes se escuda en los efectos del alcohol ${ }^{24}$.

Textos que recogen declaraciones de políticos, de especialistas, de representantes policiales, de columnistas... El llamado periodismo de citas da sentido a una gran cantidad de textos periodísticos. Las declaraciones cruzadas de los políticos, las cifras -en ocasiones también contradictorias ${ }^{25}$ - dadas por organismos como el Ministerio del Interior, la Policía, el Defensor del Pueblo, los debates cruzados entre columnistas, las argumentaciones de especialistas... estuvieron presentes en las páginas de ambos periódicos durante el 2002.

\section{Una Nueva Concepción de la Seguridad}

Ya hemos visto que el vínculos discursivos como el que nos ocupa, no son puros y no permanecen aislados ni del contexto social, ni del mediático.

Algunos de los conceptos teóricos más interesantes que apuntan a la continuidad e hibridación que existen entre los discursos pueden ser el concepto de arco discursivo manejado por Antonio Bañón (2002), con el que se pone de manifiesto los vínculos discursivos que existen entre discursos incluso contradictorios o el de trama de la facticidad que propone Van Dijk (1997). Ambos señalan la necesidad de evitar considerar aisladamente los discursos de manera que, al hablar del discurso sobre la responsabilidad inmigrante en el aumento de la delincuencia predominantemente en los textos analizados, estaremos relacionándolos también con los textos en el que se manejen discursos sobre las mafias y el tráfico de personas o los 'ilegales'.

Nos parece interesante en este punto una breve digresión acerca del concepto ilegal pues nos parece uno de los prolegómenos más importantes del proceso de criminalización que analizamos.

En algunos textos periodísticos se hace una valoración entre los buenos y los malos inmigrantes. Los buenos inmigrantes ${ }^{26}$ (los que tienen documentación)

24 Este titular es un año posterior a nuestro análisis (11/03/03) pero es de $\mathrm{ABC}$. Las diferencias con respecto al tratamiento de la vinculación entre inmigración y delincuencia entre cabeceras
de referencia como las que abordamos aquí con otras más populistas como $A B C$, es un estudio interesante que aún está por hacer.

25 Durante el 2002 hubo incluso un desmentido de Valdivieso, Director General de la Guardia Civil, negando las cifras de detenidos extranjeros que proponía el Ministerio del Interior.

26 ‘los otros inmigrantes. Más de 30000 extranjeros han creados sus propias empresas y 820000 ya están dados de alta en la Seguridad Social (subt)' (EL MUNDO, 29/09/02).

Revista Internacional de Culturas y Literaturas, enero 2005 
son trabajadores, emprendedores, sumisos... y los malos (los ilegales) son vagos, peligrosos, delincuentes, extraños... por lo que se justifican las políticas contra la inmigración ilegal ${ }^{27}$ que se están adoptando en toda Europa. Son discursos políticos que responsabilizan individualmente a los inmigrantes de su situación, enfatizando el corto plazo y no atendiendo a otras causas estructurales reales.

El problema es que, como han demostrado autoras como Calavitta (1998), la dicotomía entre legales e ilegales no es real, porque la gran mayoría de los inmigrantes, debido principalmente a una legislación represiva y policial, pasan por períodos de legalidad e ilegalidad, por lo que es fácil generalizar los miedos que provocan el ser ilegal al conjunto de los inmigrantes. ${ }^{28}$

El binomio delincuencia inmigración es un discurso especialmente eficaz. Es una generalización muy creíble y políticamente rentable que está relacionada con otros discursos acerca de los inmigrantes, que se manejan en los terrenos del desconocimiento y del miedo.

'La lucha contra la inmigración ilegal' (y otras luchas paralelas como la lucha contra la delincuencia o la lucha contra el terrorismo) es un arma electoral poderosa, como demostró sobradamente Le Pen en las pasadas elecciones francesas. El crecimiento de los discursos xenófobos en Europa y la progresiva asunción de los partidos democráticos de parte de sus presupuestos para no perder votos, es otra de las claves que podrían explicar el éxito de la relación delincuencia - inmigración. Como también lo es el contexto que podríamos llamar 12 de Septiembre, que ha generado una nueva concepción de la seguridad que enfatiza el miedo, la desconfianza en lo distante culturalmente y la necesidad de protección constante por parte del Estado.

\section{Algunas Conclusiones}

La necesidad de entender los textos de análisis en su contexto comunicativo responde al interés de comprender la importancia y el valor que se le dio al discurso mediático que vinculaba la inmigración con la delincuencia y también para reconstruir este discurso mediático en un contexto social más amplio, ya que formó parte de lo que fue el presente social del momento, en el sentido de que muchos de los discursos

27 'Defensa incluye "la inmigración ilegal masiva" entre las amenazas para la seguridad nacional (EL PAÍS, 18/11/02)

28 Posteriormente abordaremos la relación que existe entre el miedo y el vínculo entre delincuencia e inmigración. Ahora nos interesa ejemplificar la indefensión y el miedo que padecen en genera los inmigrantes como colectivo cada vez más marginalizado y perseguido, de forma que hasta se han podido documentar enfermedades mentales específicas de los inmigrantes derivadas de una cronificación de ese miedo: 'Síndrome de Ulises, la enfermedad del emigrante Los psiquiatras observan un aumento de los trastornos psíquicos entre los inmigrantes (subt). "Como si me hubieran apuñalado" (Destacado) [profundo miedo, delirios de persecución] (EL PAÍS, 26/11/02); ‘Un sin papeles con depresión se quema a lo bonzo en Barcelona (EL MUNDO, 24/12/02) cotidianos, que quedaron reflejados- por ejemplo en las sucesivas encuestas de opinión del CIS $^{29}$ en las que se preguntaba por la sensación de inseguridad ciudadana o por el miedo a lo extranjero- recogían una creciente desconfianza y miedo a los inmigrantes. Y podemos ir más allá, aún hoy, y en parte por el seguimiento y la trascendencia que se le dio a ese vínculo, los discursos de criminalización de los inmigrantes son nuestro presente puesto que al hablar de inmigración no es difícil que esa asociación mental se haga presente.

La idea de 'hablar de lo que hay que hablar', porque es lo importante según los medios de comunicación y con 'las claves con las que hay que hacerlo', es decir, de profundizar en la función socializadora de los medios de comunicación nos ayuda a entender el concepto discursivo de comunidades de sentido. Compartir conocimientos comunes que muchas veces se (re)producen en los medios de comunicación, ayuda a la cohesión social, como también lo hacen la sensaciones como las que despiertan este tipo de discursos. Textos como los que nos ocupan apelan sobre todo al miedo, argumento fácilmente demostrable si echamos un vistazo al léxico que se maneja en todos ellos: delincuencia, violencia, asesinatos, robos, inmigración...

Para autores como Varela y Álvarez Urías (1987), el miedo en las actuales Sociedades Complejas tiene una función cohesiva muy importante frente a los que se sitúan en los márgenes de la sociedad. Además, los miedos sociales están teniendo en la actualidad una especial efervescencia discursiva: la islamofobia, el choque de civilizaciones, la lucha contra el terrorismo, la lucha contra la delincuencia... y se está convirtiendo en una baza electoral internacional muy potente.

Un concepto especular del teórico comunidades de sentido es el cotidiano sentido común, concepto sobre el que se ha reflexionado también desde la Criminología crítica para entender lo que significa el delito hoy. Como nos recuerda la teoría del etiquetamiento, tenemos que entender los procesos sociales que se ponen en juego en el proceso de criminalización de una conducta. Es decir, analizando las prácticas sociales de instancias de control social ${ }^{30}$ como la policía, los jueces o la cárcel entenderemos, en parte, porque están sobrerrepresentados los inmigrantes en el Sistema Penal. Según este planteamiento teórico detrás del Código Penal estaría el Código Social

29 De este momento es una encuesta del CIS en la que subrepticiamente se preguntaba a los encuestados si creían que existía relación entre la inmigración y la inseguridad ciudadana ('¿está usted muy, bastante, poco o nada de acuerdo con que,, hoy en día existe en España relación entre inseguridad ciudadana e inmigración?'). En este tipo de discursos no periodísticos sino científicos (revestidos de autoridad, legitimidad y veracidad) lo interesante es destacar la relación que establece ya la pregunta, pues independientemente de lo que se responda, propone una asociación mental de la que el entrevistado no se puede zafar.

30 Este planteamiento teórico no supone que la policía, por ejemplo, sea una institución especialmente racista, mantiene por el contrario que el racismo es una relación de desigualdad estructural que afecta a todas las instituciones y sujetos sociales de nuestras sociedades occidentales. 
es decir, procesos sociales no explícitos ${ }^{31}$, que guiarían la mirada de policías, jueces y funcionarios penitenciarios hacia determinados sujetos, entre los que se encontrarían los inmigrantes, de los que socialmente se espera que sean más proclives al delito. Esas expectativas sociales tendrían repercusiones, también en sujetos como los inmigrantes, que Varela denomina frágiles, cayendo en lo que los sociólogos de la desviación denominan la Profecía que se Autocumple. Unas expectativas que formarían parte de ese sentido común no cuestionado pues estarían sustentadas en prejuicios, estereotipos sociales y binomios mediáticos como el que hemos tratado aquí.

\section{BibLIORAFía}

Abril, G., "Análisis Semiótico del Discurso", en Delgado, Juan Manuel y Juan Gutiérrez Métodos y Técnicas cualitativas de investigación en ciencias sociales, Madrid, Síntesis-Psicología, 427-463., 1995.

Aierbe, P. y Mazkiaran, M., "Análisis del tratamiento en la prensa de los términos "ilegal" y "mafias"”, en Mugak, vol. 5, 42-53, 1998.

Bañón Hernández, A. M., Discurso e inmigración. Propuesta para el análisis de un debate social, Murcia, Universidad de Murcia, 2002.

Baratta, Criminología crítica y crítica del derecho pena,. Madrid, S. XXI editores, 1989.

Calavitta, K., “Inmigration, Law and Marginalization in a Global Economy. Notes from Spain", en Law and Society Review. Vol. 32, nº 3, 529- 566, 1998.

Cea D'Ancona, M. Á. y Valles, M. S., “Los medios de comunicación y la formación de la opinión pública ante la inmigración y el racismo", en Sociedad Y Utopía. Vol. 16, 133-148, Centro de Investigaciones Sociológicas; CIRES, 2000.

Cipie, Inmigración y racismo: análisis de la radio, la televisión y la prensa en España, Madrid, Fundación CIPIE, 2001.

Cohen, S. y Youn, J., The Manufacture Of The News. Deviance, Social Problems And The Mass Media, Londres, Constable/Sage, 1980.

De Lucas, J., Puertas que se cierran. Europa como fortaleza, Barcelona, Icaria, 1996.

----, Blade Runner. El derecho guardián de la diferencia, Valencia, Tirant Lo Blanch, 2002.

Fariclough, N., Discourse And Social Change, Cambridge, Polity press, 1998.

Foucault, M., Vigilar y castigar, Madrid, Siglo XXI, 1994.

García España, E., Inmigración Y Delincuencia En España. Análisis criminológico, Valencia, Tirant Lo Blanch, 2001.

Giménez-Salinas, E., “Extranjeros en prisión” en Eguzkilore, no 7, 133-145, 1994.

31 Los implícitos son uno de los objetos de investigación preferentes del Análisis Crítico del Discurso.
Hartman, P y Husband, C., Racism and the mass media, Londres Davis-Poynter, 1974. Hess, H., “La criminalitá come mito quotidiano” en Dei deliti e delle pene, 1986.

Hirschi, T., Causes Of Delinquency, University Of California Press, 1969.

Izquierdo Escribano, A., La inmigración inesperada. Madrid, Trotta, 1996.

Lozano, J., Peñamarín, C. y Abril, G., Análisis del discurso: Hacia una semiótica de la interacción textual, Madrid, Cátedra, 1982.

Manzano Bilbao, C., El grito del otro. Arqueología de la marginación racial, Bilbao, Tecnos, 1999.

Martín Rojo, L., Gómez Esteban, C., Arranz, F. y Gabilondo, A. (eds), Hablar y dejar hablar sobre el racismo y la xenofobia, Madrid, Universidad Autónoma de Madrid, 1994.

Martín Rojo, L. y Whittaker, R., Poder decir. Perspectivas en el análisis crítico de discurso, Arrecife ed., 1998.

Roiz, M., “La construcción de la diferencia cultural de los inmigrantes en los medios de información”, en Documentación Social, vol 97, 177-197, 1994.

Santamaría, E., “(Re)presentación de una presencia. La "inmigración” en y a través de la prensa diaria", en Archipiélago vol 12, 65-72, $1993 .$.

Sutherland, White- Collar Crime, Nueva York, 1949.

VV. AA., "Inmigración y cárcel”, en Panóptico, no 3 (2002), Barcelona, Virus.

Van Dijk, T., La noticia como discurso. Comprensión, estructura y producción de la información, Barcelona, Paidós, 1990.

----, Prensa, racismo y poder, México, Universidad Iberoamericana1995.

----, Racismo y análisis crítico de los medios, Barcelona, Paidós, 1997.

----, El discurso como interacción social. Estudios del discurso: una interacción multidiplinaria, Vol. 2 , Barcelona, Gedisa, 2000.

Varela, J. y Álvarez Uría, F., Sujetos frágiles. Madrid, FCE, 1987.

Wacquant, L., Cárceles de la miseria, Buenos Aires, Manantial, 2000.

Wagman, D., "Estadística, delito e inmigración”, en Página Abierta, nº 129 , Madrid, 2002.

Wodak, R., Análisis crítico del discurso, Barcelona, Gedisa, 2003.

Zapata, R., El turno de los inmigrantes. Esferas de justicia y políticas de acomodación Madrid, IMSERSO, 2002 